\title{
Los enigmas del campo
}

\author{
Jorge Alonso
}

ARTURO WARMAN, 2001

\section{El campo mexicano en el siglo XX}

FCE, México, 2001, 263 pp.

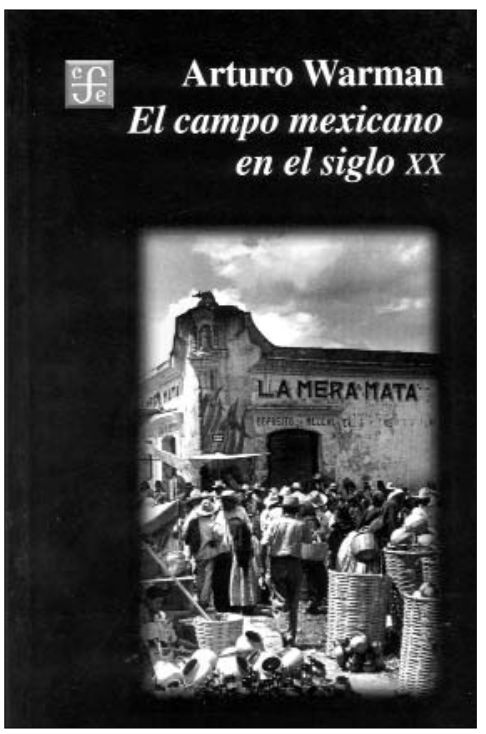

Aturo Warman escribió una agu1 da revisión del desenvolvimiento y los conflictos del agro mexicano en el último siglo. Aunque el autor precisa que este libro lo concibió, documentó y redactó cuando se desempeñaba como servidor público, hay en él todo el sello de un académico, en particular de un antropólogo que sabe analizar y escribir. Se convierte así en la obra con la que se reintegra al mundo académico, sin que se note que lo haya dejado. La intención confesada fue realizar una historia, objetivo logrado magistralmente. Pero tampoco se trata de una historia convencional, pues se
JORGE ALONSO: CIESAS-Occidente.

Desacatos, núm. 13, invierno 2003, pp. 177-187. profundiza interdisciplinariamente en la comprensión de las estructuras socioeconómicas y políticas. El libro se encuentra muy bien documentado. La abundancia de cifras no lo hace pesado, porque hay un estilo agudo, ágil, ácido, muy crítico, pero también esperanzado. El lector es conducido con seguridad y sin tropiezos en los laberintos de censos y series estadísticas. Toda esta información es situada con precisión. Se advierten sus límites, pero también sus alcances. A través de sabias combinaciones e inferencias se van revelando diversos fenómenos y sus dimensiones. El autor evalúa, pondera y discute las distintas series estadísticas. Todos los sectores que se mueven en el agro mexicano son tratados. Se da cuenta de los cambios que ha ido sufriendo la legislación agraria, sus contextos y contradicciones. También se abordan las transformaciones de las políticas agrarias y sus consecuencias. El autor rechaza interpretaciones maniqueas. Busca la complejidad en cada etapa. Se abre a la polémica, lejos de fáciles argumentos 


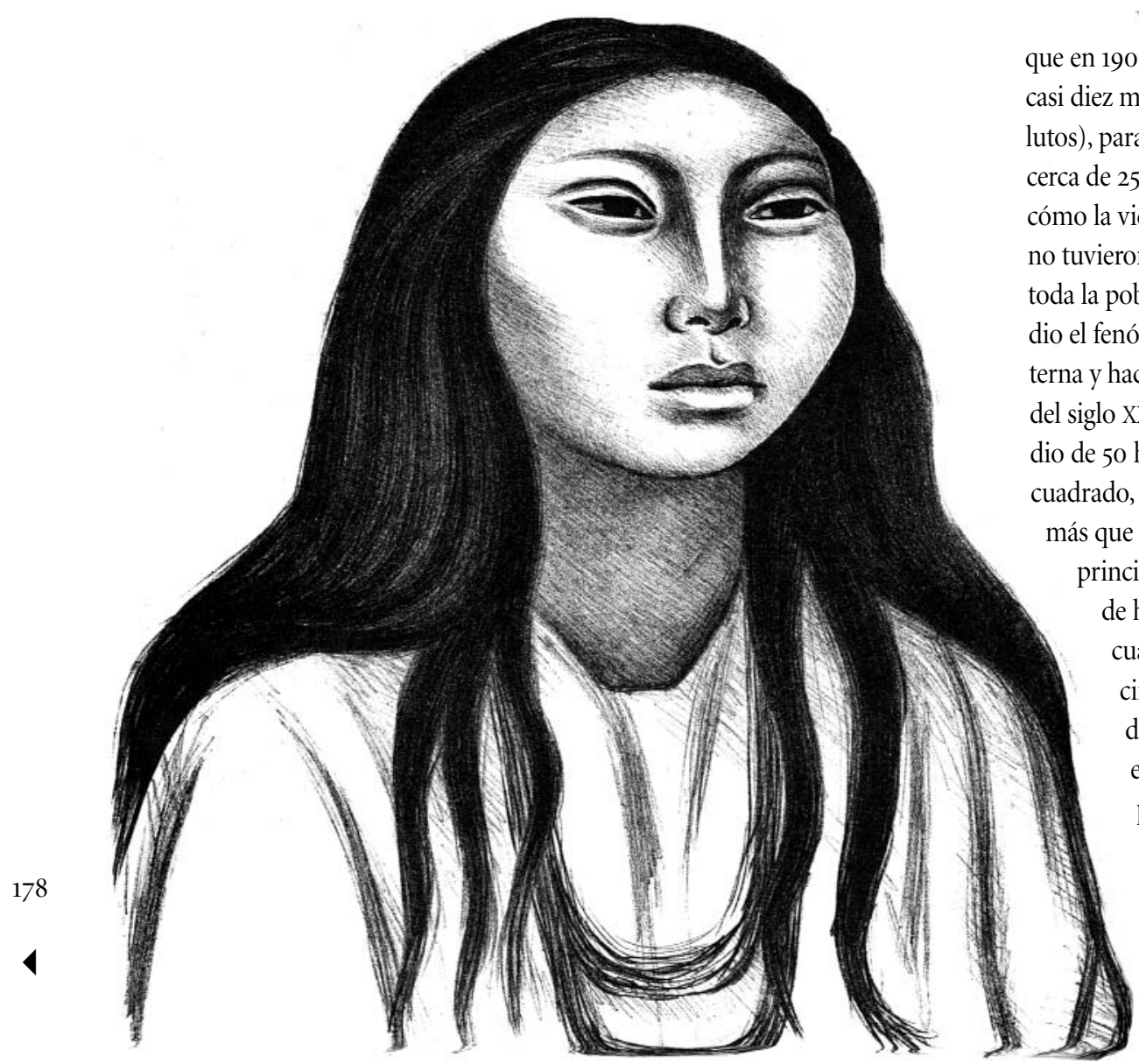

Raúl Anguiano, Ná K’in, 1951.

y sobre todo rehuye ideologizaciones. Hay una síntesis de los principales debates teóricos. Con realismo crítico se ubican los papeles que desempeñan el mercado y el Estado, y su relación a través de una sociedad que debería ser muy activa para enfrentar los retos presentes.

El libro confirma la transformación profunda de la estructura social y económica de México durante el siglo XX. Los principales ejes del análisis son la población rural, el reparto de la tierra, el producto agropecuario y forestal, la relación entre el minifundio y la pobreza rural, y el papel que desempeñan los principales actores en el campo: el gobierno, los empresarios y de manera particular, los campesinos.

El manejo de las cifras permite apreciar el tamaño de los cambios. Al inicio del siglo XX en México un $72 \%$ de la población vivía y trabajaba en el campo. Cien años después esa proporción ha descendido hasta el 25.3\%. La distancia entre lo rural y lo urbano se fue haciendo mayor en casi todos los aspectos de la vida social. Mientras
* Para tener un punto de comparación, nos podemos remitir a los datos que J. Habermas proporciona en uno de sus últimos escritos (La constelación posnacional, Buenos Aires, Paidós, 2000), en el que apunta que en los países de la OCDE el porcentaje de personas ocupadas en una agricultura altamente subvencionada ha caído por debajo del $10 \%$ de la población activa. Habermas señala además otras dos cuestiones. La primera se refiere a que la decadencia del campesinado ha trastocado la tradicional relación entre el campo y la ciudad; y la segunda, a que el proceso de urbanización está destruyendo la ciudad misma. 
zación de la vida en el campo. Calibra el problema de la dispersión y descubre sus patrones. El autor es muy cuidadoso en la presentación de la población indígena. Nos dice que el México indígena y rural tienen mucho en común. Aunque el tema indígena excede los propósitos del trabajo emprendido, es tratado profesionalmente. Warman está convencido de que si los mexicanos tenemos que caber sin pobreza en nuestro territorio, debemos respetar la diversidad. Este respeto ha de darse en un marco de cambio o transformación, pues de lo contrario no existirá un verdadero respeto sino una condena a la exclusión.

En el siglo XIX la concentración de la propiedad de la tierra fue la tendencia dominante en el país. En el siglo que acaba de terminar predominó la redistribución y la fragmentación. El autor hace ver cómo la reforma agraria fue un proceso de incorporación política de los campesinos y el Estado. Pero esta incorporación subordinada no concluía con la posesión definitiva, pues el ejidatario no era propietario sino usufructuario de tierras de la nación. No obstante, las restricciones impuestas a los ejidatarios no se respetaron. La venta y renta ilegales de tierras ejidales fue un fenómeno común. Pese a ello, se llama la atención de que la mayoría de los ejidatarios, sigue todavía trabajando directamente su parcela. Actualmente entre el 10 y el $15 \%$ de la superficie territorial de México (con una gran diversidad de climas y de lluvias y escurrimientos) es cultivable. Hay tierras que deben dejarse descansar, otras que no son generosas ante los cultivos. El autor muestra cómo la frontera agrícola está cerrada. La ganadera, con $25 \%$ del territorio, también se encuentra ya en esa circunstancia. A lo largo de todo el libro se halla una preocupación ecológica y se dan cifras escalofriantes de la peligrosa destrucción del medio ambiente. Se han ido perdiendo rápidamente áreas forestales. El autor hace un repaso histórico del reparto de tierras. También ve cómo se fue modificando la propiedad privada y se incrementó la propiedad social, por tiempos y regiones. Con datos probados va desbaratando mitos. Presenta la complejidad de la desigualdad en esta propiedad.

Warman discute cómo la equidad distributiva ha sido muy vulnerable con el paso del tiempo. Aumenta la población, se introducen innovaciones técnicas, se consigue trabajo remunerado, la gente emigra, se renuevan las generaciones de campesinos. Todo eso fue tropezando con la rigidez de parcelas con límites fijos y con los propios límites legales. Se fueron haciendo ajustes. Pero arraigó la parcela individual en la propiedad social. Ofrece las cifras de cuántas parcelas tienen los diversos grupos de ejidatarios, para apuntar cómo se da una cierta relación entre el número de parcelas en manos de un titular y la desigualdad en la tenencia de la tierra ejidal. También se descubre que la circulación de la tierra de propiedad social recurrió a la transmisión de parcelas con más frecuencia que a la sucesión de unidades de dotación compactas y completas, lo cual también incidió en la desigualdad interna de los ejidos y en el crecimiento de los minifundios.
Sólo la quinta parte de quienes trabajan en el campo no tiene tierra de su propiedad. Warman demuestra que, si la distribución de la tierra cultivada fuera perfectamente equitativa, todos los productores serían minifundistas. Su estudio concluye que la concentración de la propiedad agraria y de recursos para elevar su productividad, que existen, no constituyen el problema fundamental del campo hoy en día. Los retos son otros, y el autor los irá desentrañando a lo largo del libro. Además de la herencia que fragmentaba, también se dio un importante proceso de venta de tierras. Los compradores casi siempre fueron ejidatarios del mismo ejido o vecinos. Casi una cuarta parte de los ejidatarios actuales pagaron por su parcela. Warman precisa que no hay tierra más cara por hectárea que la de las parcelas ejidales pequeñas. Tienen un mercado restringido pero permanentemente interesado en los vecinos que quieren ampliar su superficie porque han procreado muchos hijos que aportan trabajo y porque, por otras causas, cuentan con los recursos para dicha adquisición. Los datos comprueban que estos compradores no están interesados en cualquier tierra, sino en la cercana. La venta de parcelas genera desigualdad. El autor examina la idea extendida de que la compraventa de parcelas acabará por aniquilar al ejido. Sin embargo, las cifras muestran que son muy pocas las parcelas ejidales que tienen atractivo comercial para la producción agropecuaria, pues son demasiado pequeñas y caras para la escala de una empresa. Lo más probable es que la circulación de parcelas 
entre ejidatarios contribuya a la permanencia del ejido aunque con cambios importantes.

Se discute también el valor de la tierra. Éste representa una porción cada vez más baja en la inversión agropecuaria, la cual se destina en su mayor proporción a instalaciones, maquinaria, insumos, tecnología, empaque y comercialización. El autor llama la atención de que el descenso en la proporción que la tierra representa en la inversión agropecuaria genera una paradoja. Cuando el ejidatario con buena tierra no tiene los recursos o apoyos para hacerla producir comercialmente, con frecuencia la renta barata y mucho más si aparte se le ofrece empleo; pero la vende muy cara porque es su único patrimonio. En cambio las parcelas ejidales sí ofrecen atractivos deñable, pero es más baja que la que se presenta cuando se hacen comparaciones con otros conjuntos. Otra de las novedades que ha arrojado la información es que un 18\% de los titulares de la propiedad ejidal son mujeres, que encabezan unidades de producción agropecuarias como madres solteras o por emigración laboral de los varones. Ha habido un traspaso de la agricultura a manos féminas mientras los hombres buscan actividades remuneradas.

Un punto destacado en el libro es la relación entre el reparto de la tierra y la población indígena. Pese a la clara intención y el énfasis restitutorio que se originó en la Revolución Mexicana, la reforma agraria encontró serias dificultades para realizar restituciones a las comunidades despojadas. El grave problema estaba en probar la propiedad original. De las resoluciones que dieron origen a cerca de treinta mil núcleos agrarios menos de 500 fueron restituciones. El autor hace distinciones entre ejido y comunidad agraria. Pero ésta acabó por asimilarse al ejido como forma de organización de propiedad social. Se confirma una falta de atención para la regularización de los núcleos indígenas por parte de autoridades agrarias. Los conflictos agrarios más agudos de los últimos tiempos se concentran entre los indígenas que enfrentan a particulares o ejidatarios no indígenas, y que agregan la dimensión étnica al conflicto agrario. Hubo muertos en el camino del reparto de tierras, y los conflictos por tierra todavía son regados con sangre.

El autor se adentra en una cuestión antes no tratada y muy estrujante: las implicaciones del envejecimiento de los titulares de la propiedad social. Analiza los cambios en la esperanza de vida. Para los viejos la parcela proporciona refugio, autonomía, seguridad, ninguna en abundancia, ni siquiera con suficiencia. Pero para la mayoría de los campesinos esa base precaria es la que sigue organizando la vida y la actividad de la familia. Por eso mismo, los ingresos obtenidos fuera, aunque sean mayores, son considerados como complemento. La avanzada edad de los ejidatarios y comuneros los ha hecho conservadores y resistentes a los grandes riesgos e innovaciones. Defienden su seguridad frente a la incertidumbre. Warman señala que no hay un sistema de seguridad social para mujeres y hombres del campo (no tienen seguro médico como el que reciben obreros y empleados); jamás recibirán pensión, jubilación o retiro por la vida de trabajo. Con sus propios recursos tienen que hacer frente a la vejez, a sus achaques y costos, sin apoyo del Estado. Existe una gran desigualdad y también una gran injusticia. Con capacidades físicas mermadas y sin apoyo de pensión o jubilación, la titularidad de la parcela se manifiesta como fuente de poder y autoridad para asegurar algún ingreso y alguna ocupación, para no quedar a merced de una caridad establecida por una lealtad no exenta de rencores. El agotamiento y culminación del reparto agrario, la clausura acelerada de las pocas áreas de colonización abiertas, el deterioro acumulativo de los recursos naturales, la carencia de pensiones o jubilaciones que aseguren la sobrevi- 
vencia y la dignidad de los viejos alejan al campo de las transformaciones que requiere. Un campo pobre, avejentado y conservador se repite a sí mismo en vano intento por ser lo que fue.

El libro analiza la gran propiedad de principios de siglo y la actual. Los cambios son abismales. Si antes la acumulación era el problema, a finales de siglo XX lo es la fragmentación. Se llega al dato de que hay más propietarios que viviendas rurales. No existe un sector significativo de trabajadores de la tierra sin derechos de propiedad. Pero si bien es cierto que en el agregado nacional no hay trabajadores del campo sin tierra, sí se ven condiciones locales y particulares, esa aseveración ya no puede sostenerse. Hay regiones en las que los campesinos sin tierra son un hecho evidente, a veces muy combativo. En esta discusión se establece la relación de la familia campesina y su composición con la tenencia de la tierra. Warman argumenta que el reparto de la tierra no puede sustituir al desarrollo, a la política social y a la democracia para enfrentarse a la pobreza, a la falta de oportunidades, a la exclusión política y a la discriminación. La tierra tiene que producir más, pero para eso requiere transformaciones.

Se estudia el crecimiento con desigualdad. Se realiza un seguimiento del comportamiento que tienen durante todo el siglo la agricultura, la ganadería, la silvicultura y, en alguna medida, la pesca. Como en los otros puntos prosigue una sugerente combinación entre tiempo y espacio. Hay una preocupación en el autor porque los datos nacionales no desdibujen las especificidades regionales. A inicios del siglo

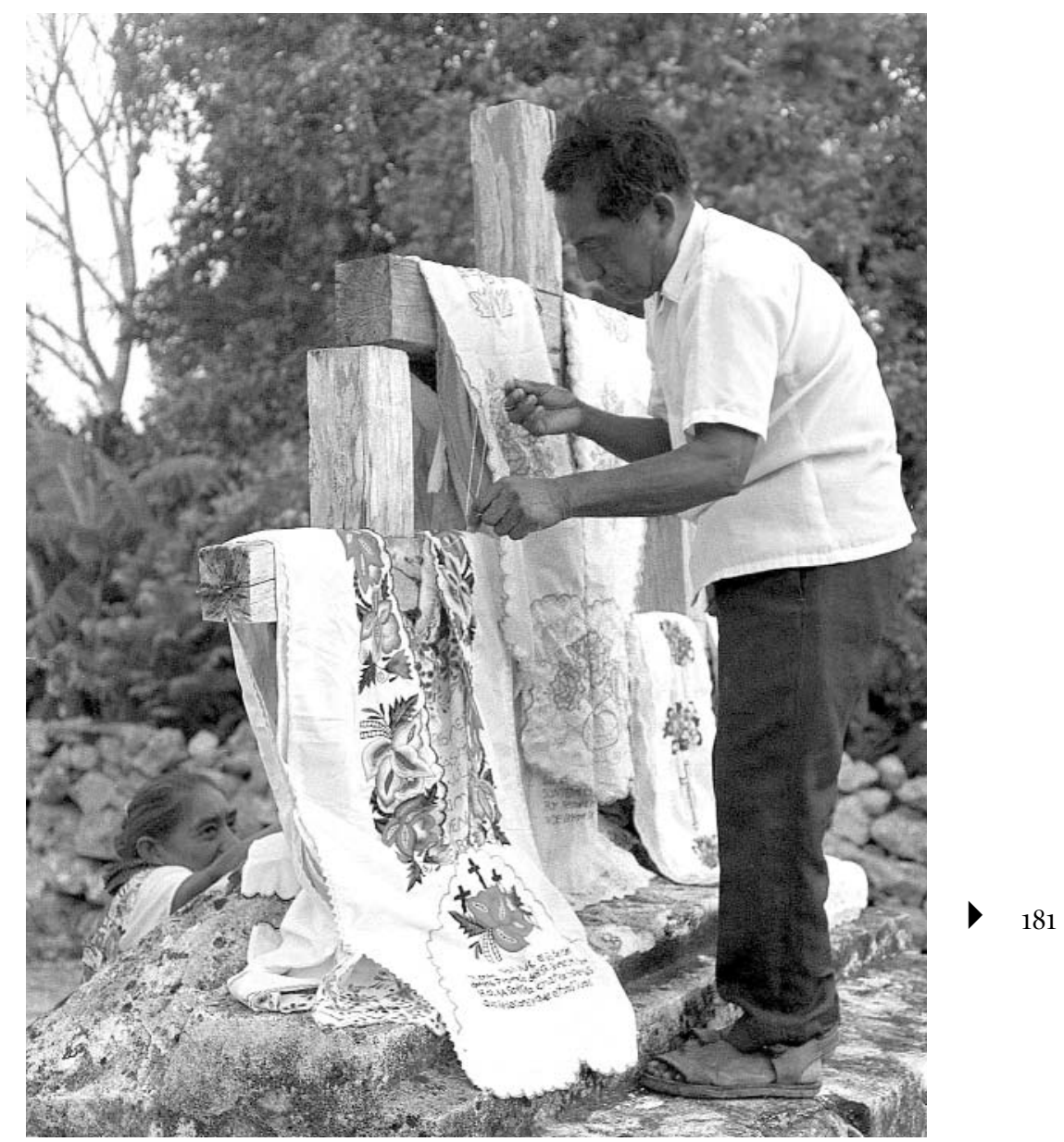

Cambio de sudarios a las cruces protectoras del pueblo, Xocén / Christian Rasmussen.

XX el producto agropecuario directo representaba casi un 30\%, y a finales del mismo bajó seis veces. El valor de la producción agropecuaria en el 2000 representó un poco menos del $6 \%$ del producto nacional. El ingreso promedio de los que trabajan en actividades agropecuarias no llega ni a la tercera parte del ingreso per capita promedio en el país. El autor va delineando los rasgos de la grave desigualdad existente en el campo. Advierte que analíticamente conviene separar desigualdad de injusticia, si se intenta moderarlas. Se presentan y discuten estructura de producción, precios agrícolas, diversidad de cultivos y sus rendimientos. El autor apunta que el crecimiento sostenido del producto agropecuario es condición indispensable, aunque no suficiente, para disminuir la pobreza e inequidad. Muchas de las fuentes de crecimiento se han ido agotando. La incorporación de nuevas tierras al cultivo es un dato del pasado, no una alternativa. Lo mismo ha sucedido con 


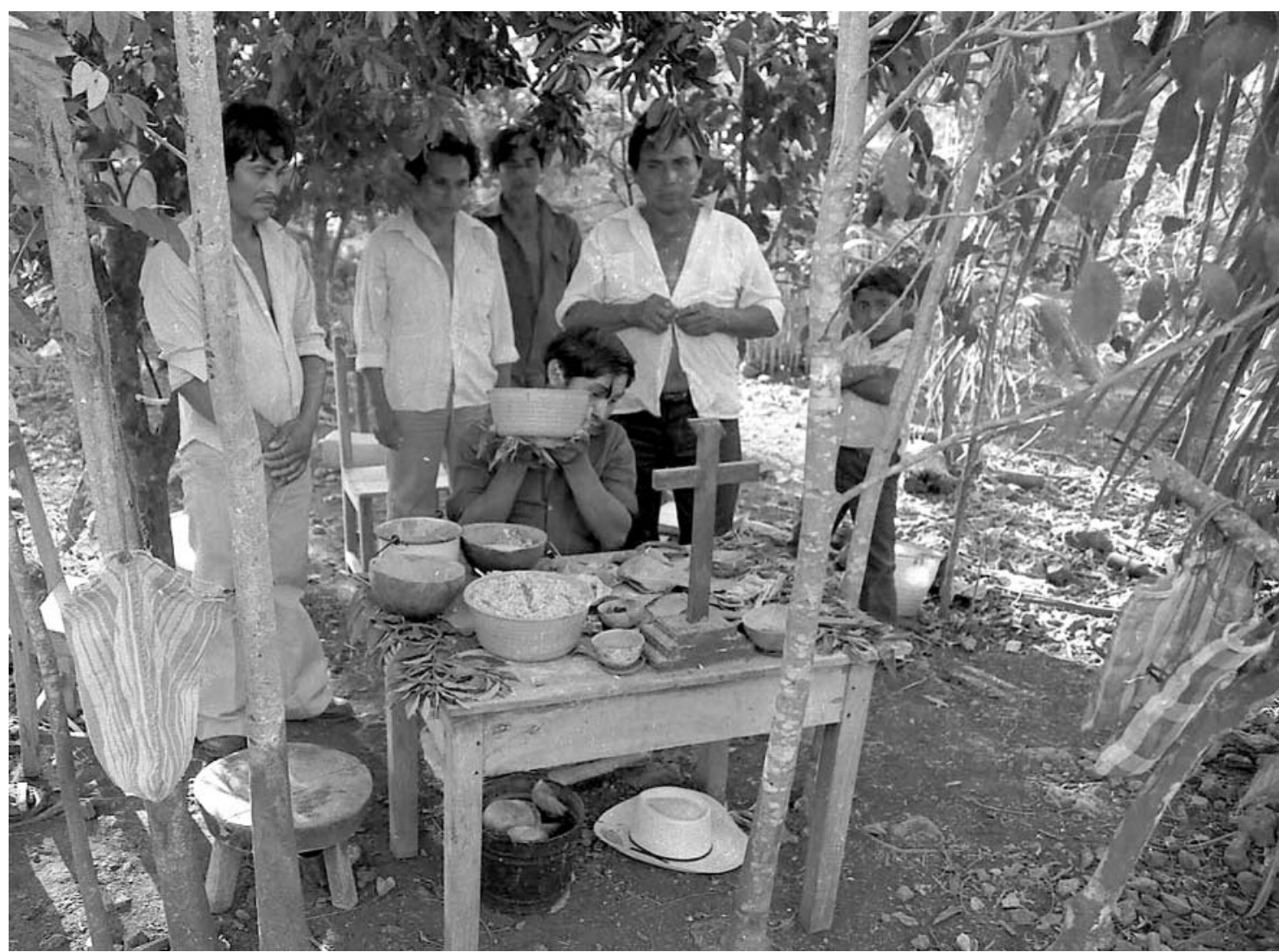

Festejo al santo huinik, pueblo de Xocén / Christian Rasmussen.

la irrigación. Se necesita la transformación de la estructura productiva, mayor inversión, ampliación de mercados. Hay ventajas competitivas, pero se ven boicoteadas por los viejos sistemas de financiamiento, acopio e intermediación. Se requiere investigación de excelencia. Las políticas agrarias no pueden ser uniformes. El complejo mosaico geográfico, humano, cultural, étnico y socioeconómico en que se practican las labores agropecuarias conforma un conjunto de nichos diversos y plurales. No hay recetas generales. El autor recalca que el crecimiento rural va a costar, pero el desarrollo del campo es asunto serio y ya no podemos perder tiempo y recursos en improvisaciones.

Recordando la fórmula de análisis de la familia campesina como unidad de producción-consumo, Warman nos lleva por los complejos procesos que se han ido formando y cambiando a lo largo del siglo XX. Nos hace ver cómo de las unidades de producción rurales, el $85 \%$ son campesinas: familias que comparten trabajo y consumo, que forman parte de una comunidad de pares en ejidos o propiedades particulares que participan en el mercado de bienes, dinero y poder. La cuestión del autoconsumo lleva direc- tamente al maíz. El autor sostiene que sigue siendo cierto que hay una gran concordancia entre ser campesino y cultivar maíz. Pero como lo hace en todo el libro, no permite que frases lapidarias caigan en simplismos. Warman muestra cómo detrás del maíz hay muchas diferencias. En este libro todos los análisis cuantitativos son llevados a lo cualitativo. El autor demuestra que más de dos terceras partes de los productores rurales son minifundistas dedicados a una gran variedad de cultivos.

El estudio sobre el minifundismo es implacable. Se ven todas sus implica- 
ciones en cuanto a la composición de las familias, la producción, combinación con trabajo asalariado fuera del predio, el papel que desempeñan las remisiones de dólares desde la migración internacional, el complejo tejido de redes sociales en torno al minifundio. Pese a todas las estrategias de sobrevivencia, que son muchas, variadas y de mucha invención social, la correlación entre el minifundio y la extrema pobreza - aunque no es absolutallega a presentarse como abrumadora. La ley establece que la herencia o sucesión de la parcela y los derechos ejidales se deben transmitir a uno solo de los sucesores sin repartirse. Pero desde la lógica de muchos campesinos la fragmentación de la herencia es justa y natural. Hay tensión en el sistema hereditario de los campesinos mexicanos de fines de siglo. Lo pequeño no es tan bello como a veces se quiere presentar. Erradicar la extrema pobreza en el campo equivale a combatir el minifundio en que se incuba y reproduce. Pero otra vez, frases tan contundentes son examinadas por el autor con sumo cuidado, pues no es suficiente eliminar el minifundio sino que se debe promover a los minifundistas para que alcancen un nivel productivo o ingresos que generen un bienestar sostenido.

En las vías para combatir el minifundismo pueden surgir nuevas contradicciones que agraven la pobreza. Por esto mismo el autor examina las vías para la superación del minifundio. La pobreza que se concentra en el campo es el reto más urgente. Se discuten los problemas para la medición de la pobreza, que se ha vuelto un piso resbaloso. Pareciera que la exageración es más frecuente que el ocultamiento de cifras. Por las cifras más confiables parece que más de la mitad de los hogares rurales padecen pobreza. En el campo no hay servicios ni oportunidades, siempre distantes. Para recibirlos hay que salir de la localidad. La dispersión profundiza y reproduce la pobreza. Combatir la pobreza del campo mexicano es un proceso dilatado que rechaza las demagogias. Warman ve que el minifundio puede cambiar de signo, dejar de ser un refugio generador de la pobreza para convertirse en factor de bienestar con pocas modificaciones en sí. Pero eso sólo puede darse cuando el minifundio deja de ser el eje de la actividad para sobrevivir y se convierte en el complemento del salario o del ingreso que se obtiene en actividades no agropecuarias. Otro grave déficit es que la escasa investigación científica no ha atendido a la producción en el minifundio, lo quel podría resolver problemas de esta índole. Hay opciones de asociaciones entre los minifundios, pero con base en sus propias valoraciones y respetando la libertad. Warman se lamenta de que haya pocas organizaciones al servicio de los productores, y muchas de las existentes son paternalistas o suplantan las decisiones. Se examinan vías para superar las restricciones del minifundio: la compactación, la elevación de la producción y productividad complementadas por el apoyo técnico y de asociación, la agricultura por contrato, y se deja abierta la puerta para la indagación de otras más.

Otros temas que examina el autor son las afirmaciones de que a finales del siglo XX los campesinos mexicanos están peor que a principios del mismo, así como los augurios de nuevas, masivas y cruentas revueltas. Contrapone estas opiniones a datos y tendencias para disminuir el ánimo propagandístico. Concluye que hay que legislar mucho y en serio para el campo, y garantizar el cumplimiento de la ley con eficacia y justicia. Indaga cuáles son los papeles que ahora le corresponden al Estado para que no repita políticas mal informadas y peor realizadas. Warman está convencido de que la debilidad de la democracia es complemento frecuente de las políticas públicas inadecuadas.

El autor indaga a los tres principales actores del agro mexicano: el gobierno, los empresarios y los campesinos, y hace ver cómo uno de los papeles fundamentales en este campo lo desempeñó el Estado. Reparto agrario, instituciones de todo tipo para dotar de tierras, irrigar, dar crédito, acopiar, comercializar, fijar precios, etc., fueron acciones que corrieron a cargo del Estado mexicano. Un elemento esencial fue el relativo a la organización corporativa de los campesinos. La intervención en el campo por parte del gobierno fue redituable para sustentar el proyecto nacional de tránsito de una sociedad agraria a una industrial. En el accionar estatal se generaron no pocas contradicciones que el libro va abordando y cuestionando. El gobierno, la opinión pública y sobre todo las centrales campesinas en la segunda mitad del siglo creyeron que la inquietud en el campo surgía de la demanda de la tierra, pero no se dieron cuenta de que esa era la única arena de lucha y nego- 
ciación abierta por las rígidas estructuras corporativas. Mientras tanto, la crisis profunda de producción y vida rural no era atendida. Se recetó más de lo mismo: incremento del gasto, intervención pública, burocracia, subsidios; pero el remedio no llegaba a la raíz. El libro analiza cada uno de los elementos de la crisis. El papel de una irrigación onerosa, descuidada e ineficiente es presentado con crudeza. Las líneas más dinámicas han utilizado sin miramientos pozos profundos con consecuencias de destrucción de mantos acuíferos y con resultados de salinidad de la tierra. Actualmente la irrigación agrícola consume la mayor parte del volumen del líquido y del esfuerzo público que concentra los subsidios en pocas manos, las mismas de siempre. La recuperación económi- tiza el autor. Periodo tras periodo presidencial va pasando por la lupa esclarecedora de Warman.

La prolongada crisis del campo quedó opacada por la grave crisis económica de los años ochenta. La posición del campo declinó en el interés general. Apareció un nuevo movimiento campesino centrado no en la tierra sino en la producción. Aparejado con esto, la crisis mostró que el gobierno ya no tenía los recursos ni el consenso para dirigir directamente la actividad económica. El modelo corporativo se agrietaba y resultaba ineficaz. En el campo el crecimiento excluyente depositado en las élites y en las dirigencias alcanzó sus límites. Dejó de cumplir con sus funciones económicas y dejó al descubierto profundas inequidades. Las salidas habían sido falsas y habían agravado la situación. En este contexto el autor estudia las reformas agrarias de 1992. Para 1997 las solicitudes de dotación habían sido jurídicamente culminadas y se buscaron opciones para grupos demandantes de atención.

Warman es enfático en sostener que el conflicto por la tierra ha sido superado y que ya no forma parte de la agenda inmediata del campo. No obstante, es consciente de que puede revivir si no se sostiene el crecimiento económico general, si no se generan los empleos suficientes, si el crecimiento de la producción rural no se reactiva de manera importante y sostenida con una mejor distribución de los ingresos en el campo. El análisis lleva a concluir que si los conflictos rurales del siglo que terminó fueron agrarios, el del nuevo que inicia serán hidráulicos.
El libro está lleno de frases ingeniosas que culminan en revisión rigurosa de datos. Una de esas frases es que "en el crédito el chivo sigue suelto pero casi ya no queda cristalería". Se esclarece cómo al terminar la intervención pública en los mercados fue necesario crear un sistema alternativo de apoyo a los productores. Como en todos los temas, hay una descripción detallada de lo que ha consistido el programa denominado Procampo, sus implicaciones y sus problemas. Entreveradas con las descripciones van fríos análisis lejanos de cualquier discurso político. Los pendientes también se señalan sin tapujos: el más importante tiene que ver con la equidad. No hay alegato respecto al campo mexicano que no sea examinado, desmenuzado y ponderado.

Así es tratada la cuestión de la apertura comercial y del enfrentamiento con productores externos subsidiados. Se calibran los subsidios en ambas partes teniendo en cuenta las condiciones de los productores. Las conclusiones suelen ser despiadadas. Las élites productivas han recibido internamente subsidios comparativamente más elevados que sus competidores externos, sin que se hayan mostrado capaces de competir con ellos. Warman sostiene que ese es precisamente el problema más grave del crecimiento proteccionista, concentrador y excluyente, que propicia y genera la reproducción de la pobreza en la mayoría para favorecer a una minoría ineficiente, poderosa y conservadora. La salida es nítida: hay que reintegrar a los productores la conducción del desarrollo, cosa que va avanzando entre inercias. En cuanto al punto de la insatisfechas. La gran cobija del Estado no alcanzaba para cubrirlo todo, sinte- 
organización rural, la anterior fórmula ya es inoperante, aunque presente. Se ha ido creando un vacío sin que quede claro quién lo puede llenar.

Una vez que se ha realizado un riguroso balance del campo mexicano, el autor termina con la delineación de tres escenarios a los que conducen las tendencias que se fueron perfilando a lo largo del libro. El primero es malo, el segundo es triste pero soportable, y el tercero, optimista. El autor considera que el escenario catastrófico es improbable pero no imposible. Este supone presión adicional sobre la tierra y el resurgimiento del enfrentamiento agrario cuando ya no hay tierra susceptible de reparto ni márgenes significativos para su redistribución. En el libro se ha hecho ver que no hay campesinos desposeídos ni solicitantes de tierra como grupo importante y creciente de la población. Se vio también que es muy probable que el relevo generacional contribuya a la compactación de la tierra en la medida en que muchos sucesores se ocupen en actividades distintas a las agropecuarias. Pero la demanda de tierras puede surgir por otras causas, como las movilizaciones políticas. Ya que en el campo hay insatisfacción, descontento y mucho agravio, su manipulación puede conducir a sectarismos e intolerancias. Hay organizaciones políticas que quisieran volver al pasado. Las viejas centrales campesinas pueden pretender volverse interlocutoras exclusivas y privilegiadas. Quieren convertirse en las voces que deben ser oídas, cuando las voces mayoritarias en el campo están dispersas, desarticuladas y sin representación. La derecha podría intentar la

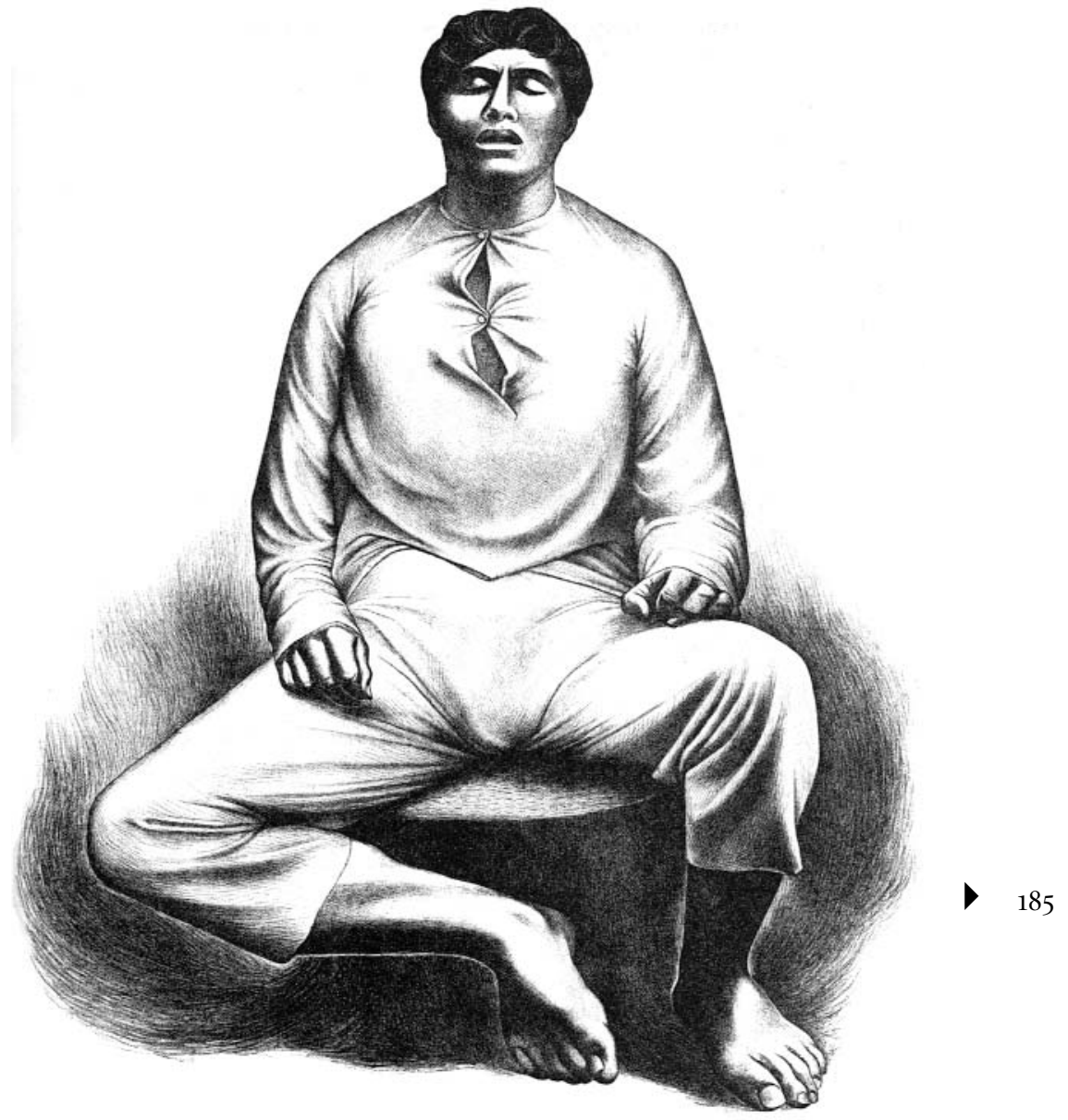

José Chávez Morado, Cadáver sentado, 1939.

imposición de la propiedad privada como la única forma legal de tenencia de la tierra, sin límites ni restricciones, la privatización a ultranza.

Warman sostiene que la probabilidad del futuro catastrófico radica en la débil representación plural y democrática de la sociedad rural. La clase política nacional está remota, distante y desinteresada, mal informada sobre el campo, y es capaz de asumir las versiones más disparatadas para procesarlas en función de intereses partidis- tas o de burocracias políticas. Los agentes políticos del campo permanecen arraigados a la estructura corporativa. No son representantes ni intermediarios eficaces entre el mundo agrario y la arena política nacional actual. No fueron escogidos por sus bases, más bien esos grupos eligieron a esas bases y las agruparon. El autor hace aquí un análisis de la democracia representativa y la participativa en los ejidos y municipios rurales. Cuando el partido de Estado va siendo sustituido 
por una democracia pluralista las conexiones viejas entre las formas de representación agraria han ido perdiendo eficacia. Warman ubica los riesgos mayores en la debilidad de la representación política en el campo, en la preeminencia de las burocracias políticas. Ahí ve que se abren espacios para decisiones ajenas, mal informadas, voluntaristas, para un verticalismo fundamentalista. Los riesgos de la catástrofe los ve remotos, pero no dejan de estar presentes.

El segundo escenario supone que el esfuerzo para transformar el campo ya se agotó. La tierra será vista por muchos como seguro de la vejez. El mercado de tierras será restringido. Se vislumbran episodios y destellos del surgimiento de nuevas fuerzas en el campo pero todavía no con claridad ción de un sistema de retiro para el campo, por el cual se deje la tierra como refugio y pueda pasar a manos más jóvenes. El autor hace estimaciones de cuánto costaría esta solución, que aunque no barata, puede estar en el rango del costo del Progresa o Procampo. Llama a que se estudie con seriedad dicha propuesta.

Warman sostiene que se requiere la promoción de una red técnica y científica para la producción minifundista cuyas soluciones sean ofrecidas no por burócratas. La participación directa de los productores en la red es indispensable para que se abran reales opciones. La adopción de nuevas técnicas o cultivos necesita respaldo.

Otro de los puntos del tercer escenario tiene que ver con la organización cooperativa horizontal flexible que recoja las mejores experiencias; como esto no puede surgir desde la base, se sugieren catalizadores. Otro elemento importante para que pueda darse este escenario es el relativo al financiamiento. Se requiere de un crédito flexible y de propósito general no vinculado sólo a un producto sino al conjunto de la unidad con muchas y diversas actividades productivas. Hay también opciones de asociaciones cooperativas de ahorro y préstamo. Se propone una redefinición del Procampo.

Otra cuestión delicada se refiere a la política de irrigación. Tanto en esto como en la conservación de los suelos hay una inquietud y propósito ecologista laudable en el autor. Propone reforestar, proteger cuencas, limpiar las corrientes de agua y sus depósitos, aclarar el aire, impedir la desaparición de plantas y animales únicos... Hay que comenzar ya, si queremos detener el grave deterioro ecológico que hemos producido. La conservación y restauración de la naturaleza requiere obras y mano de obra, que pueden ofrecer los campesinos.

Un punto fundamental es el relativo a la democracia: la participación de los campesinos es uno de los medios para evitar los desencuentros. Se tienen que definir con precisión y transparencia los programas públicos para el campo, sus objetivos y destinatarios, para corregir la falta de equidad. El combate a la pobreza debe ser otro de los elementos, pero no como hasta ahora, en que el desarrollo productivo para el combate a la pobreza es difuso. Warman insiste en que el desarrollo libre y democrático de los pueblos indígenas es condición ineludible para el combate a la pobreza. El autor también propone revisar y reformar las leyes laborales para el trabajo rural y agropecuario, en donde se reconozca su especificidad y se otorguen protección y garantías efectivas.

Warman recuerda que el sacrificio del campo ya no es necesario para mantener bajos los precios de los alimentos para la población urbana, porque de eso se ha encargado el mercado global. Se abren condiciones para un trato justo al campo. El escenario optimista implica una dinámica de crecimiento compartido y sostenido, regiones fortalecidas por su diversidad, un campo de productores jóvenes que desplieguen iniciativas y corran riesgos apoyados por asociaciones activas y democráticas. El libro no lo dice, pero obviamente uno de los graves obstáculos para el escenario optimista jante a quienes están protegidos por la seguridad social. Propone la forma- 
es un panorama de crisis económica que atenta contra el empleo. La recesión afecta a todos, y con mayor fuerza a los más desprotegidos. Valdría la pena examinar lo que ha estado pasando con el precio en el mercado internacional de importantes productos agropecuarios: café, piña, azúcar, etc., y las perspectivas para estos productores. Habría que profundizar entre la relación de grupos agrícolas y empresarios, a la luz de la crisis de la industria azucarera. En las perspectivas del libro convendría indagar además el proyecto denominado Plan Puebla Panamá.

Hay otro problema que habría que analizar. Un argumento muy poderoso que impulsó las reformas de 1992 tiene que ver con la legalización de prácticas inveteradas en el agro mexicano. Siguiendo esa lógica nos encontramos que las organizaciones indígenas de varios puntos del país, integrantes del Congreso Nacional Indígena (CNI), desde la tribuna de la Cámara de Di- putados en abril del 2001 arguyeron que las modificaciones que demandaban, consideradas en las reformas propuestas por el documento de la Cocopa, correspondían a prácticas en comunidades indígenas. En su octava Asamblea Nacional de noviembre del 2001 el CNI argumentó que la base de autonomía de los pueblos indígenas se encontraba en la defensa de la tierra y del territorio, y recalcó que la propiedad comunal de dichos territorios, la organización comunal, el trabajo colectivo, los sistemas normativos propios y todas sus expresiones culturales eran elementos constitutivos de sus pueblos y de la autonomía que cotidianamente ejercían. Esto indica que hay otras prácticas que todavía reclaman una legislación específica, pues los integrantes del CNI rechazan la que aprobó el Congreso de la Unión en el 2001.

El siglo XXI mexicano se ha abierto con un grave malestar entre los cam- pesinos que han resentido el flagelo de un inicuo mercado global que protege los productos agrícolas de los países más desarrollados y afecta los precios de los principales productos agrícolas del resto del mundo. Han resurgido nuevas organizaciones para expresar la protesta de los más desprotegidos en el agro. Los males vienen de atrás, del último tramo del siglo XX. Faltaría hacer este balance.

Este apresurado paso sobre la penúltima obra de Arturo Warman ha querido destacar la multiplicidad de elementos tratados para invitar a estudiar un libro que hace un apretado pero completo estudio de una de las realidades importantes para la historia del país. El libro es provocador de discusiones con fundamento. Hay que aceptar ese reto y entender la construcción de su articulado argumento. Su discusión debe iniciarse con la ponderación de sus razones. 